\title{
Toward zero: Deep sternal wound infection after 1001 consecutive coronary artery bypass procedures using arterial grafts: Implications for diabetic patients
}

Teresa M. Kieser, MD, ${ }^{\mathrm{a}}$ M. Sarah Rose, PhD, ${ }^{\mathrm{b}}$ Uthman Aluthman, MD, ${ }^{\mathrm{a}}$ Marlene Montgomery, RN, Thomas Louie, MD, ${ }^{\mathrm{d}}$ and Israel Belenkie, $\mathrm{MD}^{\mathrm{e}}$

Objective: Coronary artery bypass graft $(\mathrm{CABG})$ surgery with arterial conduits is considered optimal. A deterrent to bilateral internal thoracic artery (BITA) grafting is the risk of deep sternal wound infection (DSWI). We introduced infection prevention measures sequentially, attempting to reduce DSWIs. The aim was to determine (1) if the absence of DSWIs in the last 469 of 1001 consecutive operations was significant; (2) which measures explained the change; and (3) the impact of diabetes.

Methods: The measures included internal thoracic artery (ITA) skeletonization, no bone wax, wound irrigation, 1 observer per case, harmonic scalpel harvest of ITAs, vancomycin paste on sternal marrow, iodine-impregnated skin drapes, chlorhexidine-alcohol skin preparation, no BITA grafts in obese, diabetic women, more off-pump procedures, aseptic wound care, and marrow irrigation before sternal approximation.

Results: Mean age was $65 \pm 10.4$ years, $78 \%$ were male, $34 \%$ had diabetes, and $34 \%$ were obese. The first 532 patients had 16 DSWIs $(3 \%)$ and the subsequent 469 had none $(P<.001)$. Analysis of the data suggested that the first 11 measures likely contributed to the absence of DSWI and less likely, the twelfth. Key measures were likely chlorhexidine-alcohol use and avoidance of BITAs in obese diabetic women who had a 10-fold higher DSWI rate than the other patients $(21.4 \%$ vs $2.0 \%)$. Other diabetics, including obese men, had no increased risk of DSWI.

Conclusions: The measures applied caused a substantial reduction in DSWIs. Key measures included the use of chlorhexidine-alcohol and avoidance of BITA grafting in obese diabetic females. These measures reduced DSWIs after BITA grafting in most diabetics. (J Thorac Cardiovasc Surg 2014;148:1887-95)

See related commentary on pages $1896-8$.

For more than 25 years, the standard of care for coronary artery bypass graft $(\mathrm{CABG})$ conduits has been the use of 1 internal thoracic artery (ITA) and saphenous veins. However, the shorter life span of venous grafts limits the long-term benefits of the procedure. Use of bilateral ITAs (BITA), although known to improve results in all patient groups, is not common (4\% in North America, $12 \%$ in Europe, and $30 \%$ in Japan). ${ }^{1}$ Reasons for limited use of BITAs include longer operating times, technical challenges, perceived

\footnotetext{
From the Departments of Cardiac Sciences and Surgery, ${ }^{\mathrm{a}}$ Libin Cardiovascular Institute of Alberta; Rho Sigma Scientific Consultants ${ }^{\mathrm{b}}$; Infection Control and Prevention, ${ }^{\mathrm{c}}$ Alberta Health Services; Department of Internal Medicine, ${ }^{\mathrm{d}}$ University of Calgary; and Departments of Cardiac Sciences and Internal Medicine, ${ }^{\mathrm{e}}$ Libin Cardiovascular Institute of Alberta, Calgary, Alberta, Canada.

Disclosures: Teresa M. Kieser reports consulting fees and lecture from Medistim USA and Medistim ASA, and consulting fees from Ethicon Endosurgery. Thomas Louie reports consulting and lecture fees from Optima Pharma and grant support from Cubist and Actelion. All other authors have nothing to disclose with regard to commercial support.

Received for publication Oct 8, 2013; revisions received Jan 21, 2014; accepted for publication Feb 3, 2014; available ahead of print March 7, 2014.

Address for reprints: Teresa M. Kieser, MD, Foothills Medical Centre, Room C814, 1403, 29th St NW, Calgary, Alberta, Canada T2N 2T9 (E-mail: t.kieserprieur@ ucalgary.ca).

$0022-5223 / \$ 36.00$

Copyright (c) 2014 by The American Association for Thoracic Surgery

http://dx.doi.org/10.1016/j.jtcvs.2014.02.022
}

conduit-coronary perfusion mismatch, and risk of deep sternal wound infection (DSWI). The latter is considered a major deterrent to using BITA grafts. ${ }^{2,3}$ If this risk could be reduced to that associated with single ITA grafts, BITA grafting might be considered more often. ${ }^{4}$ Although mediastinitis is infrequent after CABG surgery $(0.4 \%$ $4 \%$ ), the associated mortality ranges from $10 \%$ to $47 \%{ }^{5}$

After sequential implementation of numerous changes designed to reduce infection rates associated with CABG, we analyzed our data to (1) verify that the perception of a reduced DSWI rate was indeed significant, (2) determine which prevention measures were responsible for the reduced rate, (3) assess the relative risk in diabetics, and (4) compare DSWI rates with those of our other surgeons who did not systematically use the same measures.

\section{MATERIALS AND METHODS}

From July 2003 to October 2012, total arterial grafting was performed where possible in all patients operated on by 1 surgeon, regardless of age, level of urgency, and comorbidities. There was continuous effort to mitigate infections by implementing sequential preventative measures. This retrospective analysis of prospectively collected data from consecutive patients was undertaken when it was noted that there were no DSWIs over 4 years, 7 months. For the first 532 patients, the DSWI rate was 3\%. This study was approved by our institutional Research Ethics Board.

\section{Surgical Details}

All operations were performed with standard cardiopulmonary bypass or off-pump using high spinal and light general anesthesia. Intermittent 


$$
\begin{aligned}
& \text { Abbreviations and Acronyms } \\
& \text { BITA }=\text { bilateral internal thoracic artery } \\
& \text { BMI }=\text { body mass index } \\
& \text { CABG }=\text { coronary artery bypass graft } \\
& \text { CI }=\text { confidence interval } \\
& \text { COPD }=\text { chronic obstructive pulmonary disease } \\
& \text { DSWI }=\text { deep sternal wound infection } \\
& \text { IEI }=\text { interevent intervals } \\
& \text { ITA }=\text { internal thoracic artery }
\end{aligned}
$$

antegrade blood cardioplegia and systemic hypothermia $\left(32^{\circ} \mathrm{C}\right)$ were used for on-pump procedures; off-pump CABG was performed with the Octopus stabilizing device (Medtronic, Inc, Minneapolis, Minn). ITA conduits were harvested and skeletonized, most with an ultrasonic scalpel (Harmonic Scalpel; Ethicon Endo-Surgery, CVD, Cincinnati, Ohio). ITAs were used mostly as in situ grafts and wrapped in papaverine-soaked gauze. Negative air pressure was used in operating rooms. Antibiotic coverage (cephazolin $2 \mathrm{~g} 30$ minutes before knife to skin, every 4 hours intraoperatively, and every 8 hours for 3 doses) was routine as was intraoperative glycemic control (4-9 $\mathrm{mmol} / \mathrm{L}$ ) by insulin infusion. Seven single horizontal sternal wires were used for a single ITA and 8 for BITA or when body surface area was greater than $2.0 \mathrm{~m}^{2}$.

\section{Deep Sternal Wound Infection}

DSWI was defined as infection involving the sternum, pericardium, and/ or mediastinum requiring 6 weeks of antibiotics with or without surgical debridement, rewiring, or muscle flap reconstruction. ${ }^{6}$ In the infectious disease literature for all types of surgery, 3 categories of surgical site infection are defined: type 1, superficial incisional; type 2, deep incisional (muscle and fascia); type 3, deep organ space, bone, and/or mediastinum. ${ }^{6}$ The DSWI definition used in this study is the same as type 3. Patients were followed for a minimum of 2 months at their postoperative clinic assessment; all DSWIs appeared before 4 weeks.

\section{Infection Prevention Measures}

Before 2003, 4 measures were in place: bone wax was not used on sternal edges and subcutaneous tissues were irrigated with a solution of bacitracin/saline before skin closure. From 1994, we limited observers to 1. Skeletonization of the ITAs began in 2000. From July 2003 onwards, 8 measures were added sequentially and continued subsequently. (1) Starting in November 2003, an ultrasonic scalpel was used to skeletonize ITAs (Harmonic Scalpel; Ethicon Endo-Surgery). Because a bloodless surgical field is required, less clot or charred tissue in the mammary bed reduces substrate for infection. (2) Starting in July 2005, vancomycin paste (2 g of vancomycin powder in 2 to $3 \mathrm{~mL}$ of saline) was applied to the sternal marrow before approximation. ${ }^{7}$ (3) Beginning in January 2006, iodineimpregnated surgical adhesive drapes (Ioban 3M, St Paul, Minn) were applied on the chest area before incision and removed at skin closure. (4) DSWIs occurred in 15 of the first 500 patients in this study; 5 were in obese (body mass index $[\mathrm{BMI}] \geq 30 \mathrm{~kg} / \mathrm{m}^{2}$ ) diabetic women. Thereafter (November 2007), only 1 ITA and radial arteries were used in this group with diabetes, either the left ITA as a Y with itself, or the radial divided into two-thirds/one-third with the one-third used as a Y graft with the left ITA and the two-thirds used as a separate graft. (5) Beginning in November 2007, operative skin preparation was changed to $2 \%$ chlorhexidine gluconate $/ 70 \%$ isopropyl alcohol (Soluprep 2\% to $70 \%$ tinted; Laval, Quebec) (instead of 10\% povidone-iodine) which was applied for at least 30 seconds over potential incision sites. Also, the night before, patients underwent skin preparation with a 6-wipe package of chlorhexidine
(Sage Products LLC, Cary, Ill). (6) Beginning in April 2008, off-pump CABG was performed in $75 \%$ of cases versus $6 \%$ before then. (7) In June 2008, wound care was changed to an aseptic technique (Figure 1). (8) Irrigating and manual cleansing of the sternal marrow before applying vancomycin paste began in September 2009, which was part of a protocol for a trial of Kryptonite bone cement ${ }^{8}$ for approximation of the sternum (15 patients). Marrow cleansing was necessary before applying the cement; this was done in all subsequent patients.

\section{Data Collection}

Systematically collected data from consecutive patients were entered prospectively into a surgical database. DSWIs were recorded prospectively by the Infectious Disease Department of the hospital. For comparison with rates from other surgeons at the same hospital, data were retrieved from our APPROACH database ${ }^{9}$ (prospectively collected data from patients enrolled at the time of cardiac catheterization and followed to assess outcomes).

\section{Statistical Analysis}

Objective 1. To determine whether there was a significant change in DSWI rate and, if so, when the change occurred. Because the surgeries were unevenly distributed over time, we used groups of 20 consecutive surgeries to model the infection rate, ensuring sufficient numbers in the denominator for adequate precision. To avoid the use of zero (for statistical reasons), the rate of successful surgeries (ie, those without a DSWI) was modeled instead of infection rates. In this case, time was considered as the sequential number representing each consecutive group of 20 surgeries. To determine our objective, a nonlinear 4-parameter logistic model was fitted to the successful surgery rate. One equation for this model is ${ }^{10}$

$$
\text { rate }=\beta_{0}+\beta_{1} /\left\{1+\exp \left[-\beta_{2} \times\left(\text { time }-\beta_{3}\right)\right]\right\}
$$

This describes a sigmoidal function that allows for an initial infection rate $\beta_{0}$ and a final infection rate $\beta_{1}$ and a gradual change over a period of time (midpoint $\beta_{3}$ ).

Objective 2. To determine which measure was key in reducing DSWIs, we considered that a change in the rate was most likely due to the measure implemented just before when the infection rate attains the right-hand asymptote (the new infection rate). This key intervention was considered necessary (but not necessarily sufficient) to reduce the rate, provided that the probability of observing a DSWI (after the last observed infection if the rate remained the same) was nonzero. Any of the measures implemented before this key intervention may also have contributed, but we were unable to determine this in this study. Similarly, it is possible that any measure implemented after this key intervention also contributed to a decreased rate, if the probability of a DSWI at this point after the last change point was nonzero.

To estimate the probability of a DSWI after the last observed infection as a function of the number of surgeries completed, we assumed that the DSWIs formed a stationary Poisson point process with mean $\lambda$. This required examination of the number of surgeries between each infection. To be considered a stationary point process, there should be no autocorrelation between the interevent intervals (IEI) and the cumulative distribution function should be exponential with rate $1 / \lambda$ where $\lambda$ is the mean of the IEI. After this assumption was checked, we calculated the probability of a DSWI for a given number of surgeries after the last infection using an exponential distribution with rate $1 / \lambda$. To examine the assumptions, we calculated the autocorrelation function of the IEIs and used a survival-type analysis to determine the distribution function of the IEI.

Objective 3. We examined whether the proportion of patients in the subgroup of obese diabetic women significantly decreased after the change point and then examined the difference in DSWI rates between this subgroup and the remainder of the patients before the change point. In both cases, we used the Fisher exact test to compare the proportions. 
Objective 4. To examine the change in DSWI rates in 2 other (overlapping) cohorts at our institution before and after the institution-wide change in operative skin preparation change to chlorhexidine-alcohol in November 2007 (several of the other measures were used by other surgeons, but not consistently) for: (1) all cardiac procedures performed by all surgeons for 3 years 4 months before the implementation of chlorhexidine-alcohol and for 8 months after, using a comparison of proportions; (2) isolated CABG surgeries performed by 8 other surgeons at this institution, over the same period as the study cohort. A Poisson regression model was used to estimate the incidence of DSWI for each surgeon and before and after the implementation of chlorhexidine-alcohol. The model included a categorical variable indicating surgeon and a binary variable indicating before/after chlorhexidine-alcohol implementation. The interaction between these 2 variables was examined to investigate whether the change in rates differed by surgeon. In the absence of a statistically significant interaction, and the absence of a statistically significant difference across surgeons, overall rates (with $95 \%$ confidence intervals [CI]) were estimated from the model from each time period.

\section{Guiding Principles}

$\checkmark$ Cardiac surgery patients are at high risk for developing surgical site infections

$\checkmark$ A protective approach will be taken in regard to wound care

$\checkmark$ Wound care is done OD (once a day) and prn after initial $48 \mathrm{hrs}$

$\checkmark$ PRN means: if oozing, if visibly soiled, if patient is incontinent, if wound edges are not well approximated.

$\checkmark$ No soaps, lotions or skin creams to be used on the incision

$\checkmark \quad$ If present, keep pannus clean and dry - dry gauze or abd pad, change BID and prn

Definition: Aseptic technique is a set of specific practices and procedures performed under carefully controlled conditions with the goal of minimizing contamination by pathogens.

\section{Aseptic Technique:}

$\checkmark$ Sterile dressing tray - sterile field

$\checkmark$ Clean gloves - no touch technique

$\checkmark$ Mask if wound is open or draining (if organisms and pus can get out, they can also get in!)

$\checkmark$ Sterile normal saline

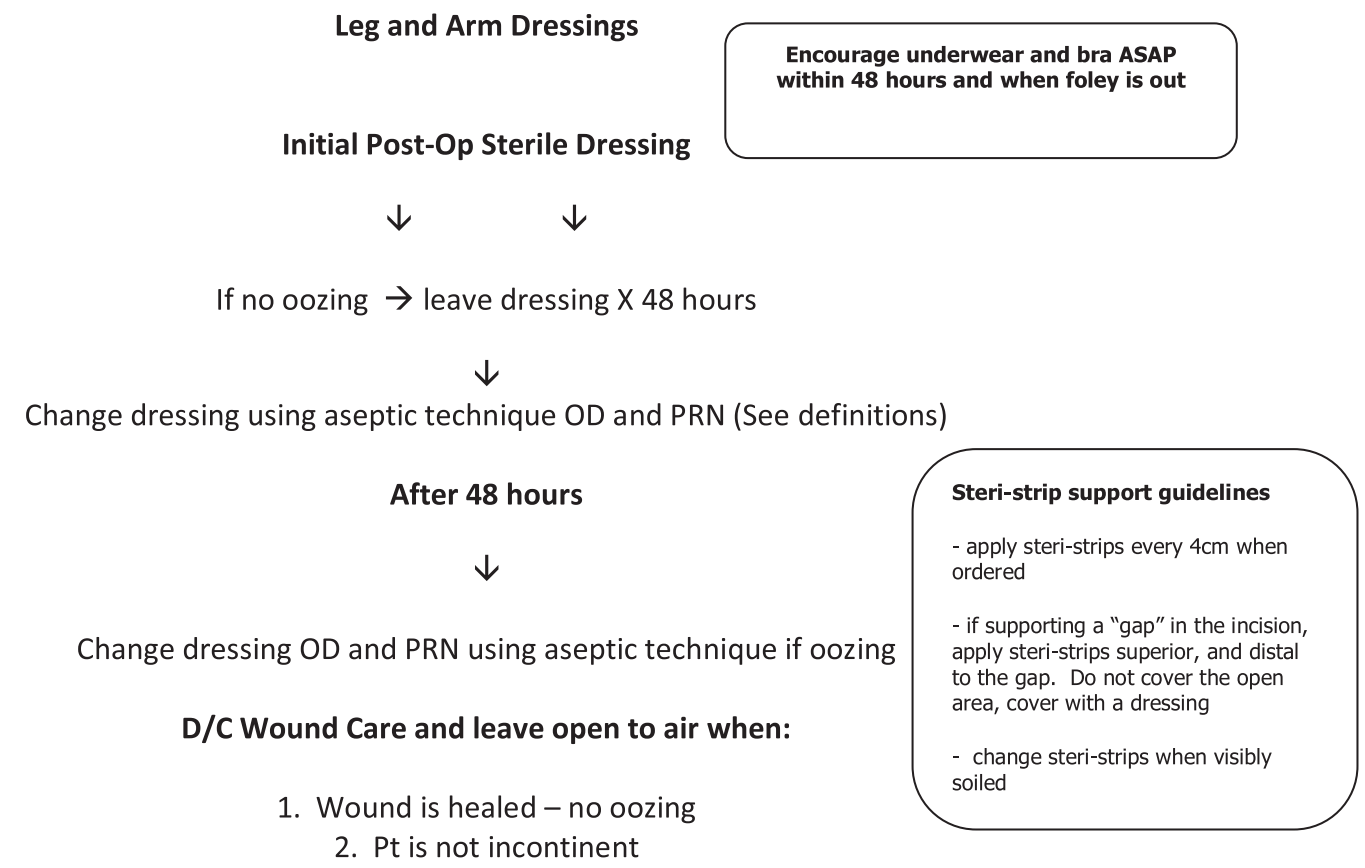

If wound is infected

$$
\downarrow
$$

Follow wound care orders in computer Order-set

FIGURE 1. Cardiac surgery wound care algorithm. $B I D$, Twice daily; $D / C$, discontinue; $P t$, patient; $C T$, chest tubes; $d / c^{\prime} d$, discontinued; $O D$, once a day; $P R N$, pro re nata [as needed]; $A S A P$, as soon as possible; $C V$-ICU, cardiovascular intensive care unit. 


\section{Sternal Dressing}

Initial Post Op Sterile Dressing

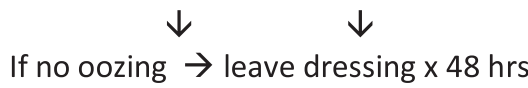

$\downarrow$

Change dressing using aseptic technique OD and PRN (See definitions)

Until CT, Telemetry are $d / c^{\prime} d$ (protection from contamination) - then leave open to air (see exceptions)

\author{
After 48 hours \\ Change dressing OD using aseptic technique (even if not oozing)
}

Encourage underwear and bra ASAP

within 48 hours and when foley is out

1. All chest tubes and lines are out

2. Wound is healed - no oozing, edges will approximate

3. Exceptions as mentioned above are not present (i.e. not trached, intubated etc.)

4. Nurse will review sternal care with patient

FIGURE 1. (Continued).

\section{RESULTS}

\section{Study Population}

From July 18, 2003 to October 16, 2012, 1001 consecutive CABG operations ( 1 patient had a second procedure 8 years later for new disease) were performed with $98 \%$ (2928 of 2987) arterial grafts. Fifty-nine operations were for singlevessel disease; $73 \%$ (689 of 942) of the remaining operations were with BITA grafts. Graft conduits consisted of $70 \%$ ITAs, $28 \%$ radial arteries, $2 \%$ venous, and 4 inferior epigastric arteries $(0.13 \%)$. The demographics of the patients are listed in Table 1 . There was less chronic obstructive pulmonary disease (COPD) $(P=.022)$, fewer active smokers $(P=.029)$, and less insulin-dependent diabetics $(P=.003)$. In 4 patients, 6 of 8 harvested ITAs could not be used because of damage and/or fragility. They were included in the analysis because they shared the presumed associated risk for infection. Twenty-six $(2.7 \%)$ patients required reexploration for bleeding, none of whom developed DSWI. 
TABLE 1. Patient characteristics: before and after the change point

\begin{tabular}{|c|c|c|c|c|}
\hline & All patients $(n=1001)$ & Before change point $(n=532)$ & After change point $(n=469)$ & $P$ value \\
\hline Off-pump, n (\%) & $388(39)$ & $37(7)$ & $351(75)$ & $<.001$ \\
\hline BITA rate excluding single-vessel disease & $689 / 942(73)$ & $358 / 504(71)$ & $331 / 438(76)$ & .122 \\
\hline \multicolumn{5}{|l|}{ Demographics } \\
\hline Mean age, y (SD) & $64.9(10.4)$ & $64.8(10.6)$ & $65.1(10.2)$ & .671 \\
\hline Male, n $(\%)$ & $780(78)$ & $409(77)$ & $371(79)$ & .402 \\
\hline Outpatient, $\mathrm{n}(\%)$ & $435(44)$ & $227(43)$ & $208(44)$ & .151 \\
\hline Inpatient, $\mathrm{n}(\%)$ & $455(45)$ & $254(48)$ & $201(43)$ & \\
\hline Emergency, n (\%) & $111(11)$ & $51(10)$ & $60(13)$ & \\
\hline \multicolumn{5}{|l|}{ Comorbidities } \\
\hline Total diabetics, $\mathrm{n}(\%)$ & $345(34)$ & $180(34)$ & $165(35)$ & .755 \\
\hline Type 1 diabetes, $\mathrm{n}(\%)$ & $58(6)$ & $42(8)$ & $16(3)$ & .003 \\
\hline Type 2 diabetes, $\mathrm{n}(\%)$ & $287(29)$ & $138(26)$ & $149(32)$ & .130 \\
\hline Hypertension, n (\%) & $691(69)$ & $361(68)$ & $330(70)$ & .411 \\
\hline Hypercholesterolemia, n (\%) & $697(70)$ & $371(70)$ & $326(70)$ & .973 \\
\hline Active smoker, n (\%) & $208(21)$ & $125(24)$ & $83(18)$ & .029 \\
\hline Ejection fraction $30 \%-50 \%, \mathrm{n}(\%)$ & $228(23)$ & $122(23)$ & $106(23)$ & .739 \\
\hline Ejection fraction $<30 \%, \mathrm{n}(\%)$ & $66(7)$ & $32(6)$ & $34(7)$ & \\
\hline Obesity: $\mathrm{BMI} \geq 35 \mathrm{~kg} / \mathrm{m}^{2}, \mathrm{n}(\%)$ & $113(11)$ & $61(11)$ & $52(11)$ & .920 \\
\hline $\mathrm{BMI} \geq 30 \mathrm{~kg} / \mathrm{m}^{2}, \mathrm{n}(\%)$ & $339(34)$ & $185(35)$ & $154(33)$ & .547 \\
\hline COPD, n $(\%)$ & $114(11)$ & $73(14)$ & $41(9)$ & .016 \\
\hline Cerebrovascular disease, $\mathrm{n}(\%)$ & $101(10)$ & $59(11)$ & $42(9)$ & .293 \\
\hline Peripheral vascular disease, $\mathrm{n}(\%)$ & $106(11)$ & $63(12)$ & $43(9)$ & .182 \\
\hline Renal disease, creatinine $>200 \mu \mathrm{mol} / \mathrm{L}, \mathrm{n}(\%)$ & $36(4)$ & $19(4)$ & $19(4)$ & 1.0 \\
\hline EuroSCORE, median (IQR) & $2.9(1.5,6.2)$ & $3.0(1.6,6.2)$ & $2.8(1.5,6.2)$ & .618 \\
\hline
\end{tabular}

$B I T A$, Bilateral internal thoracic artery; $S D$, standard deviation; $B M I$, body mass index; $C O P D$, chronic obstructive pulmonary disease; $I Q R$, interquartile range.

Operative mortality was $3.9 \%$ overall, $16 \%$ for emergency procedures, $4 \%$ for urgent operations, and $0.7 \%$ for elective procedures. Among the 16 patients with DSWIs, $6(38 \%)$ died, 4 during the first admission and 2 after early readmission.

\section{Deep Sternal Wound Infection}

There were 16 DSWIs overall $(1.6 \% ; 95 \%$ CI, 0.9\%-2.6\%). Two occurred after single ITA grafting. Fourteen DSWIs occurred after BITA grafting, all in the first 316 of 686 patients with BITA grafts ( 14 of $316,4.4 \%$; $95 \%$ CI, $2.4 \%-7.3 \%$ ). Of the 14 with BITA grafts, 9 were diabetic; 9 were male, 8 were obese including 4 with morbid obesity $\left(\mathrm{BMI} \geq 40 \mathrm{~kg} / \mathrm{m}^{2}\right)$ and $5(36 \%)$ were obese diabetic women. Treatment included debridement \pm rewiring in 6 ( 1 patient left open), sternal reconstruction with muscle flap in 2, pericardial window in 1 , vacuum-assisted closure in 1 , local wound dressing in 2 , antibiotics only for 6 weeks in 3 without wound breakdown (purulent drainage, severe sternal pain, positive white blood cell scans), and no treatment in 1 of the 2 patients with a single ITA artery graft who died quickly with purulent pleuritis/mediastinitis; the other single ITA graft patient (the last) needed only dressing changes.

\section{Detection of a Statistically Significant Change Point}

The last DSWI was in patient number 532 on April 7, 2008. The estimated 4-parameter logistic model is shown in Figure 2, A. There was a statistically significant $(P=.001)$ change in the DSWI rate from $3.1 \%$ to $0 \%$. The midpoint of the inflection was the 513th operation on November 16, 2007, and for practical purposes, we consider surgery 532, when the last infection was observed, to be the change point of infection rates.

\section{Which Infection Prevention Measures Contributed to the Decrease?}

Measures implemented just before the decrease in infection rates (April 2008) were avoidance of BITA grafts in obese diabetic women on October 12, 2007 and change to chlorhexidine-alcohol on October 30, 2007. However 1 more infection occurred after this just at the sixth measure (change to off-pump and this patient had surgery performed off-pump). Overall, the mean number of surgeries between infections was 33.25 and the number of surgeries between infections fitted an exponential distribution (Figure 2, B). The probability of observing 17 surgeries without an infection at this incidence was high $(P=.60)$ indicating that the wound care protocol may also have contributed to the decreased infection rates. The final measure listed (irrigation of bone marrow) was implemented on September 28, 2009, 155 surgeries after the last DSWI $(P<.001)$ indicating that it is less likely to have contributed substantially to the decreased infection rate, but not impossible.

To decide whether the DSWIs had been eradicated (ie, $P<.000001[1 \mathrm{E}-06]$ of observing no DSWIs after 


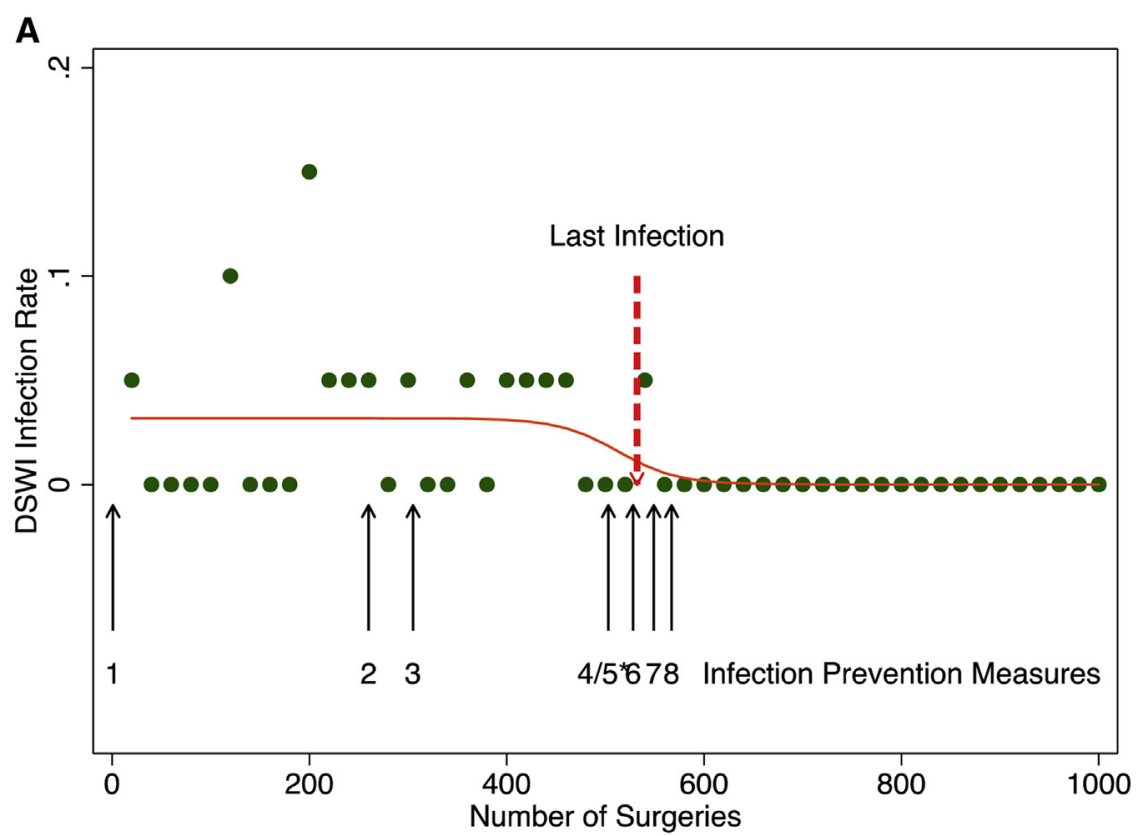

B

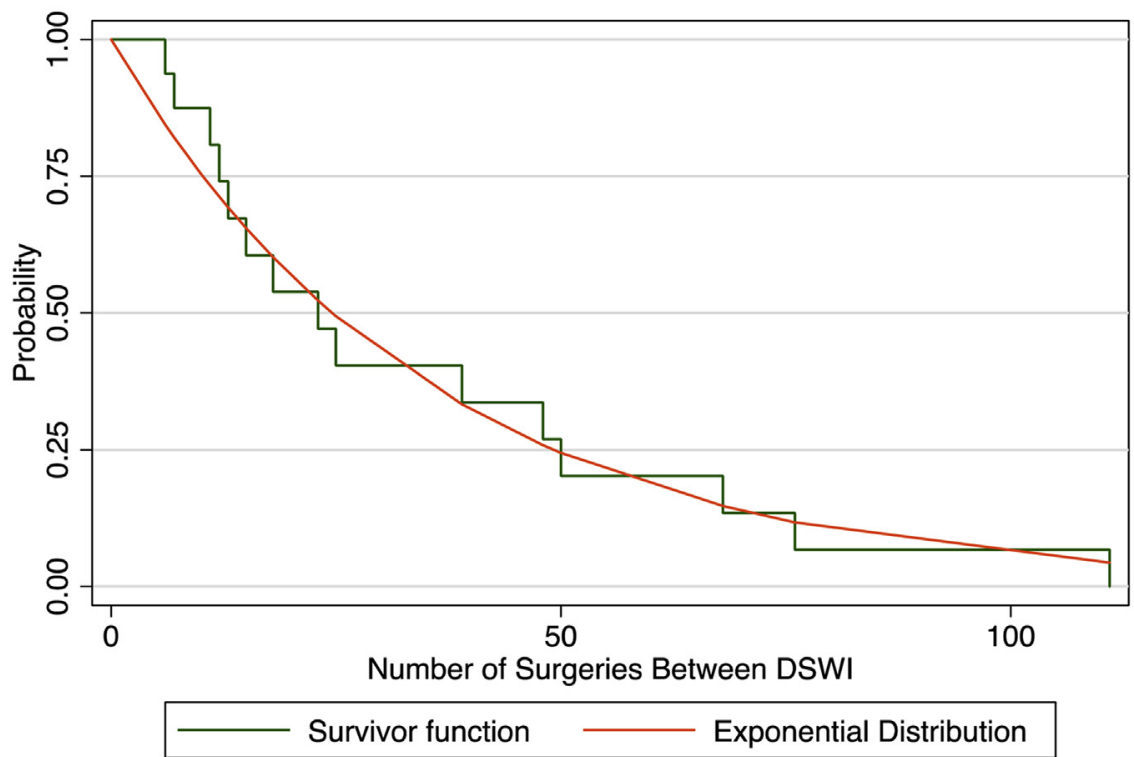

FIGURE 2. A, Infection rates per 20 consecutive surgeries (dots). The dashed red arrow indicates when the last deep sternal wound infection was observed. The black arrows indicate when each infection prevention measure (see later discussion) was implemented. *Indicates an institution-wide measure. Infection prevention measures: (1) Skeletonization of internal thoracic arteries with ultrasonic scalpel; (2) vancomycin paste applied to sternal halves; (3) use of iodine-impregnated surgical adhesive drapes; (4) avoidance of use of bilateral internal thoracic arteries in obese diabetic women; (5) preoperative skin preparation with chlorhexidine-alcohol; (6) off-pump coronary artery bypass graft was performed where feasible; (7) wound care was changed to an aseptic technique; (8) cleansing the sternal marrow before applying vancomycin paste. B, Distribution of the interinfection intervals for the first 523 surgeries: the Kaplan-Meier estimate (green line) is the estimated probability of remaining infection-free given the number of surgeries since the last infection. The red line indicates the fitted exponential distribution; ie, the probability of observing 50 surgeries or more between infections is high (about $25 \%$ ). The probability of observing 100 surgeries or more is about $5 \%$ and the probability of observing 200 surgeries or more without infection is low at $0.2 \%$. DSWI, Deep sternal wound infection.

the last 1 observed); we would have to follow an additional 460 patients after the last observed infection without another occurrence. A total of 469 surgeries were observed without infection $(P=7.48 \mathrm{e}-07$ if the infection rate had not changed) indicating that the rate of DSWI in BITA patients had decreased (and potentially been eradicated) by the combination of measures. 


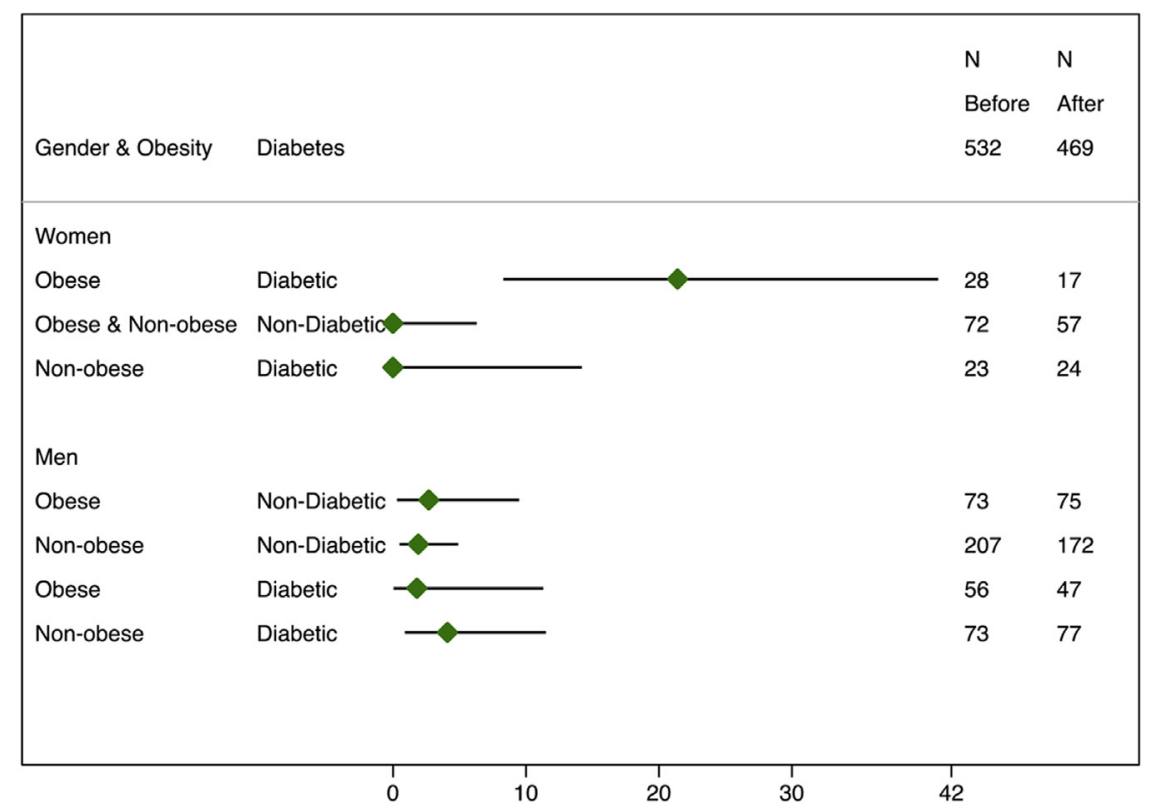

FIGURE 3. Comparison of deep sternal wound infection (DSWI) rates in men, women, diabetic and nondiabetic, obese and nonobese patients. Diamonds, DSWI rate in each subgroup before the change point. Lines indicate the confidence intervals (CI). CIs are one-sided (97.5\%) when the estimates are zero and $95 \%$ when nonzero. There is no significant effect of obesity and diabetes in men $(P=.696)$; the overall rate was $2.4 \%(1.2-4.4)$. However, obese diabetic women have a significantly higher risk of DSWI than other women $(P<.001)$. Notably, the only DSWIs in women were observed in obese diabetics. The last 2 columns indicate the number of patients in each subgroup before and after the change point. There was no significant difference within women $(P=.547)$ or men $(P=.512)$.

\section{DSWI Risk in Obese Diabetic Women}

In Figure 3 shows the DSWI rate in the subgroups identified by sex, obesity, and diabetes. After October 2007, BITA grafting was avoided in obese diabetic women and therefore the proportion of such patients relative to the total population of BITA patients $(\mathrm{N}=689)$ decreased from $5.3 \%(95 \% \mathrm{CI}, 3.2 \%-8.2 \%)$ to $1.8 \%$ (95\% CI, $0.7 \%$ $3.9 \%), P=.015$. The DSWI rate in 28 obese diabetic women before April 2008 was $21.4 \% \quad(95 \%$ CI, $8.3 \%-40.9 \%$ ), which was 10 -fold greater than that in all other patients in this first group of 532 patients combined $(\mathrm{N}=504$; DSWI rate $=2.0 \%$ [8 of 504]; $95 \% \mathrm{CI}$, $1.0 \%-3.6 \%)$. Reasons for performing BITA in 6 diabetic obese women after the changed strategy included ideal circumstances for just BITA, a BMI just more than $30 \mathrm{~kg} / \mathrm{m}^{2}$, ability to perform off-pump CABG and unawareness of a BMI of $35.5 \mathrm{~kg} / \mathrm{m}^{2}$ in 1 woman.

\section{Comparison With All Other CABG Procedures in the Same Institution}

Before the operative skin preparation was changed to chlorhexidine-alcohol (November 2007), the DSWI rate was $3.1 \%$ (139 of 4420) for all cardiac procedures for all surgeons over 3 years 4 months. Subsequently, the rate over 8 months decreased to $0.8 \%$ (6 of 818 procedures) $(P=.001)$. There was no evidence of an interaction between surgeon and the before/after November 2007 variable $(P=.415)$ or of a significant difference in rates across surgeons $(P=.127)$. The overall after/before November 2007 incidence rate ratio was 0.46 (95\% CI, 0.24-0.86) indicating that the overall rate of DSWI in isolated CABG was halved after the introduction of chlorhexidine-alcohol in November 2007, from $2.65 \%$ (95\% CI, $1.74 \%-4.02 \%$ ) to $1.21 \%(95 \% \mathrm{CI}, 0.67 \%-2.17 \%)$ but not eliminated.

\section{DISCUSSION}

In this study of 1001 consecutive CABG operations by a single surgeon with near total arterial and 74\% BITA grafting, we were able to achieve a significant reduction in the incidence of DSWIs after sequential introduction of multiple infection prevention measures. There were no DSWIs associated with the last 469 procedures, whereas the DSWI rate was $3.01 \%$ in the preceding 532 operations. To date, this is the lowest reported DSWI rate after bypass surgery. This is particularly important because of the substantial number of patients with BITA grafts. Also important is that among diabetic patients, only obese women seem to have a high risk of DSWI and that the risk in other diabetics, including obese men, is similar to the nondiabetic population.

\section{Risk Associated With BITA Grafting}

In 1990, Kouchoukos and colleagues ${ }^{11}$ first documented the relationship between BITA grafting and DSWI (which occurred in $6.9 \%$ of patients with BITA conduits, $1.9 \%$ of patients with single ITA grafts, and $1.3 \%$ of patients with 


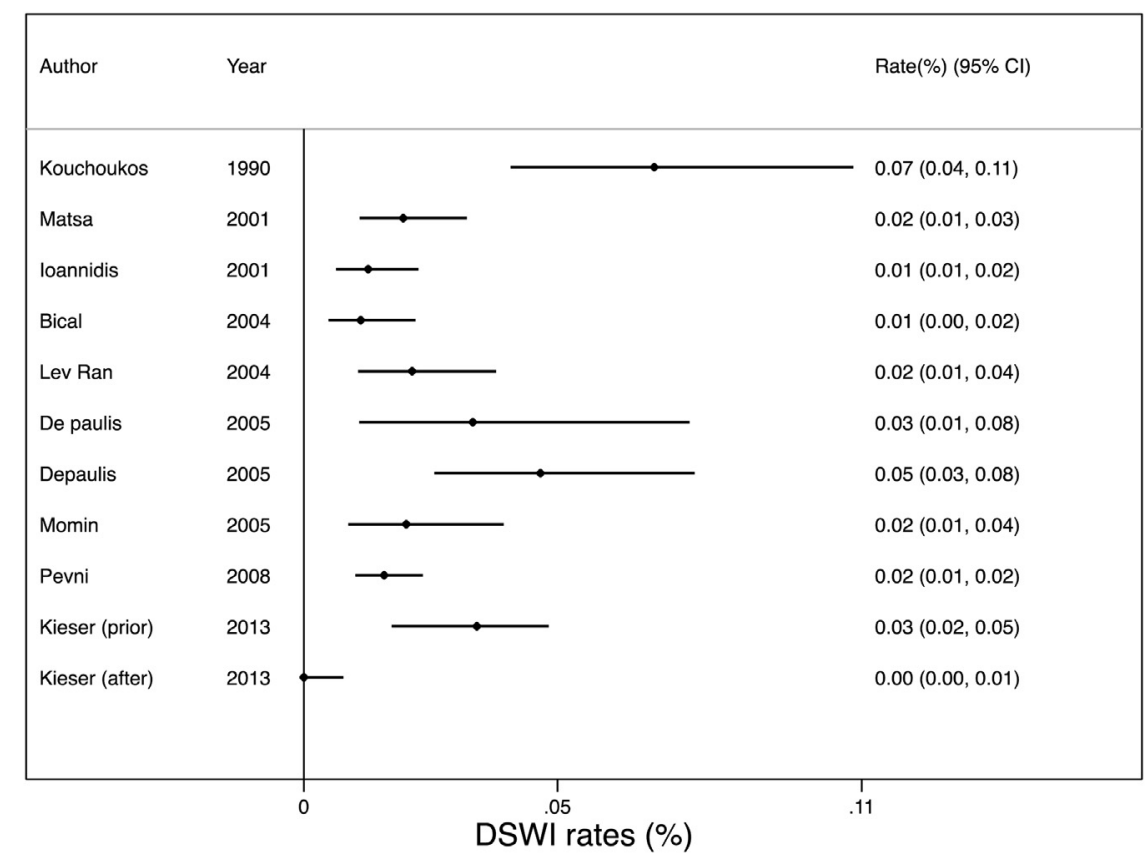

FIGURE 4. Comparison of the estimated deep sternal wound infection (DSWI) rate in this study (Kieser 2013) before and after the change point with other previously reported studies. The diamonds represent the infection rates and the lines indicate the $95 \%$ confidence intervals $(C I)$ of the estimate. Because the number of infections for Kieser 2013 (after) was zero, a one-sided $95 \%$ confidence interval is presented.

vein-only grafts). They suggested that BITA grafting was not justified (unless other conduits were not available) until they were proven superior to single ITA grafts. Subsequently, in 1999 Lytle and colleagues ${ }^{12}$ documented the long-term benefits of BITA grafting. However, there is still reluctance to use BITA grafts in diabetics even though many have verified the safety of BITA in such patients, especially if ITAs are skeletonized. ${ }^{13-17}$ Our observations add credence to the safety of BITA grafting (with respect to DSWI) and demonstrate how the DSWI rate can be lowered even further. This is particularly important in the United States; the Centers for Medicare and Medicaid Services have deemed mediastinitis after cardiac surgery a "never event" and no longer reimburse for extra care if a DSWI occurs. ${ }^{18}$

\section{Risk Associated With Diabetes}

As previously reported by Matsa and colleagues ${ }^{13}$ and stated by Lev-Ran and colleagues, ${ }^{14}$ we found only 1 subgroup of patients with an increased risk of DSWI: obese diabetic women; they had a 10-fold greater incidence of DSWI than obese diabetic men. They represented $13 \%$ of the diabetics, but had $38 \%$ of the DSWIs (5 with BITA and 1 with single ITA). Thus, our results suggest that there is no increased risk of DSWI with BITA grafting in most diabetics in whom the DSWI rate was only $1.3 \%$ and that only obese diabetic women should not undergo BITA grafting. Because 2 measures (not using BITAs in obese diabetic women and the switch to chlorhexidine-alcohol) were implemented at approximately the same time; it remains possible that just the antiseptic change was sufficient. Although this raises the possibility that the current risk may be lower in obese diabetic women than our data suggest, the continued (but low) incidence in DSWIs in patients operated on by other surgeons who also use chlorhexidinealcohol does not support that.

\section{Key Infection Prevention Measures}

The use of chlorhexidine-alcohol and avoidance of BITA grafting in obese diabetic women seem to be the key effective measures responsible for eliminating DSWIs in a substantial number of subsequent procedures. Certainly, all implemented measures may have contributed, but it was only after these 2 that the DSWI rate decreased dramatically. Even though the DSWI rate for our other surgeons was halved after the introduction of chlorhexidinealcohol, it was not eliminated, which suggests that the introduction of chlorhexidine-alcohol in November 2007 was not solely responsible for the reduction in DSWIs in the authors' patients.

Chlorhexidine-alcohol is an effective infection prevention agent. The 2011 Guidelines for the Prevention of Intravascular Catheter-Related Infections, as a Category IA level of evidence, recommends skin preparation with greater than $0.5 \%$ chlorhexidine-alcohol for intravenous or arterial line insertions. ${ }^{19}$ Several controlled trials ${ }^{20-22}$ compare chlorhexidine-alcohol with povidone-iodine in surgical patients. For general surgical patients undergoing cleancontaminated surgery, chlorhexidine-alcohol was more 
protective against superficial and deep infections but inexplicably not against organ-space infections. ${ }^{22}$

\section{BITA Grafting and DSWI}

The incidence of DSWI using skeletonized BITA grafts varied from $1.1 \%$ to $3.3 \%$ in previous studies

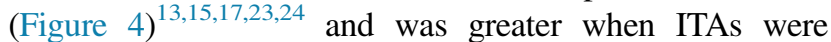
harvested in a pedicled fashion ${ }^{16,23}$ in BITA grafting, ${ }^{13,15-17,23-25}$ and lower after single ITA grafting. ${ }^{11,23}$ In our series, although the DSWI rate after BITA grafting was $1.6 \%$ for the whole group, it was $3.0 \%$ for the first 532 patients and $0 \%$ in the last 469 patients $(76 \%$ with BITA grafts).

\section{Limitations}

As is common in retrospective studies, it was not possible to control for all factors that may have changed outcomes in the 2 groups of patients. The non-DSWI group had slightly fewer active smokers, insulin-dependent diabetics, and patients with COPD; the small number of patients with these characteristics should not have affected the results. Also, general improvements over time in surgery, anesthesia, and knowledge of infection may also have helped to reduce infections. The strategy of not using BITA grafts in obese diabetic women, and the switch to chlorhexidine-alcohol were key measures. The strength of this study is that it is a consecutive all-comer population of patients in which most had BITA grafting, including most diabetics.

\section{CONCLUSIONS}

We have shown in a series of $1001 \mathrm{CABG}$ procedures with near total arterial grafting, three-quarters BITA grafts and one-third diabetics, that the risk of DSWIs can be reduced to close to zero through multiple infection prevention measures. We cannot predict a zero rate; the risk will certainly not disappear. We suggest that just as DSWI may be caused by the transgression of several barriers to infection, the incidence of DSWI may be reduced by the addition of layers of prevention. We cannot point to a single measure as being critical and speculate that multiple barrier techniques are likely necessary to optimize outcomes. DSWIs still occur in our unit at a low rate, but not in patients in whom all the measures have been implemented. It is important to emphasize that the risk was reduced in all subgroups except for obese diabetic women. Our data support the avoidance of BITA grafting in obese diabetic women; however, most diabetics may benefit from BITA grafting without increased risk of DSWI.

The authors greatly appreciate the support of the APPROACH cardiac and catheterization personnel.

\section{References}

1. Kinoshita T, Asai T. Bilateral internal thoracic artery grafting current state of the art. Innovations (Phila). 2011;6:77-83.
2. Dorman MJ, Kurlansky PA, Traad EA, Galbut DL, Zucker M, Ebra G. Bilateral internal mammary artery grafting enhances survival in diabetic patients. A 30 year follow-up of propensity score-matched cohorts. Circulation. 2012;126:2935-42.

3. Tatoulis J, Buxton BF, Fuller JA. The right internal thoracic artery: the forgotten conduit-5,766 patients and 991 angiograms. Ann Thorac Surg. 2011;92:9-15; discussion 15-17.

4. Toumpoulis IK, Theakos N, Dunning J. Does bilateral internal thoracic artery harvest increase the risk of mediastinitis? Interact Cardiovasc Thorac Surg. 2007;6:787-91.

5. Risnes I, Abdelnoor M, Almdahl SM, Svennevig JL. Mediastinitis after coronary artery bypass grafting. Risk factors and long-term survival. Ann Thorac Surg. 2010;89:1502-9.

6. Mangram AJ, Horan TC, Pearson ML, Silver LC, Jarvis WR. Guideline for prevention of surgical site infection 1999. Infect Control Hosp Epidemiol. 1999;20: 247-80.

7. Arruda MVF, Braile DM, Joaquim MR, Suzuki FA, Alves RH. The use of the vancomycin paste for sternal hemostasis and mediastinitis prophylaxis. Rev Bras Cir Cardiovasc. 2008;23:35-9.

8. Fedak PW, Kieser TM, Maitland AM, Holland M, Kasatkin A, Leblanc P, et al. Adhesive-enhanced sternal closure to improve postoperative functional recovery: a pilot, randomized controlled trial. Ann Thorac Surg. 2011;92:1444-50.

9. Ghali WA, Kundtson ML. Overview of the Alberta Provincial Project for Outcome Assessment in Coronary Heart Disease on behalf of the APPROACH investigators. Can J Cardiol. 2000;16:1225-30.

10. Reeve R, Turner JR. Pharmacodynamic models: parameterizing the Hill equation, Michaelis-Menten, the logistic curve, and the relationship between these models. J Biopharm Stat. 2013;23:648-61.

11. Kouchoukos NT, Wareing TH, Murphy SF, Pelate C, Marshall WG Jr. Risks of bilateral internal mammary artery bypass grafting. Ann Thorac Surg. 1990;49: 210-7; discussion 217-19.

12. Lytle BW, Blackstone EH, Loop FD, Houghtaling PL, Arnold JH, Akhrass R, et al. Two internal thoracic artery grafts are better than one. J Thorac Cardiovasc Surg. 1999;117:855-72.

13. Matsa M, Paz Y, Gurevitch J, Shapira I, Kramer A, Pevny D, et al. Bilateral skeletonized internal thoracic artery grafts in patients with diabetes mellitus. J Thorac Cardiovasc Surg. 2001;121:668-74.

14. Lev-Ran O, Mohr R, Amir K, Matsa M, Nehser N, Locker C, et al. Bilateral internal thoracic artery grafting in insulin-treated diabetics: should it be avoided? Ann Thorac Surg. 2003;75:1872-7.

15. Bical OM, Khoury W, Fromes Y, Fischer M, Sousa Uva M, Boccara G, et al Routine use of bilateral skeletonized internal thoracic artery grafts in middleaged diabetic patients. Ann Thorac Surg. 2004;78:2050-3.

16. Momin AU, Deshpande R, Potts J, El-Gamel A, Marrinan MT, Omigie J, et al Incidence of sternal infection in diabetic patients undergoing bilateral internal thoracic artery grafting. Ann Thorac Surg. 2005;80:1765-72; discussion 1772.

17. Pevni D, Uretzky G, Mohr A, Braunstein R, Kramer A, Paz Y, et al. Routine use of bilateral skeletonized internal thoracic artery grafting: long-term results. Circulation. 2008;118:705-12.

18. Puskas JD. Why did you not use both internal thoracic arteries? Circulation 2012;126:2915-7.

19. O'Grady NP, Alexander M, Burns LA, Dellinger EP, Garland J, Heard SO, et al., Healthcare Infection Control Practices Advisory Committee. Guidelines for the prevention of intravascular catheter-related infections. Am J Infect Control. 2011; 39(4 Suppl 1):S1-34.

20. Culligan PJ, Kubik K, Murphy M, Blackwell L, Snyder J. A randomized trial that compared povidone iodine and chlorhexidine as antiseptics for vaginal hysterectomy. Am J Obstet Gynecol. 2005;192:422-5.

21. Ostrander RV, Botte MJ, Brage ME. Efficacy of surgical preparation solutions in foot an ankle surgery. J Bone Joint Surg Am. 2005;87:980-5.

22. Darouiche RO, Wall MJ Jr, Itani KM, Otterson MF, Webb AL, Carrick MM, et al. Chlorhexidine-alcohol versus povidone-iodine for surgical-site antisepsis. $N$ Engl J Med. 2010;362:18-26.

23. De Paulis R, de Notaris S, Scaffa R, Nardella S, Zeitani J, Del Giudice C, et al. The effect of bilateral internal thoracic artery harvesting on superficial and deep sternal infection: the role of skeletonization. J Thorac Cardiovasc Surg. 2005;129:536-43.

24. Lev-Ran O, Mohr R, Pevni D, Nesher N, Weissman Y, Loberman D, et al. Bilateral internal thoracic artery grafting in diabetic patients: short-term and long-term results of a 515-patient series. J Thorac Cardiovasc Surg. 2004;127:1145-50.

25. Ioannidis JP, Galanos O, Katritsis D, Connery CP, Drossos GE, Swistel DG, et al. Early mortality and morbidity of bilateral versus single internal thoracic artery revascularization: propensity and risk modeling. J Am Coll Cardiol. 2001;37: 521-8. 